LA-UR- $98-979$

Title:

\title{
SENSITIVITY OF STABILITY INDICES TO DEALERTING
}

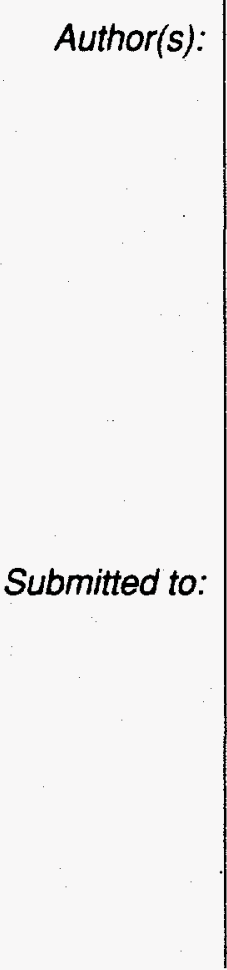

Gregory H. Canavan, P-DO

For discussions outside the Laboratory

Date: March 1998

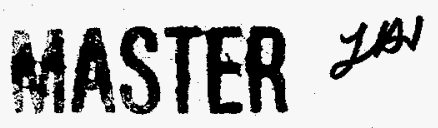

\section{DOTREUTION OF THIS DOCUMENT IS GNLMTED}

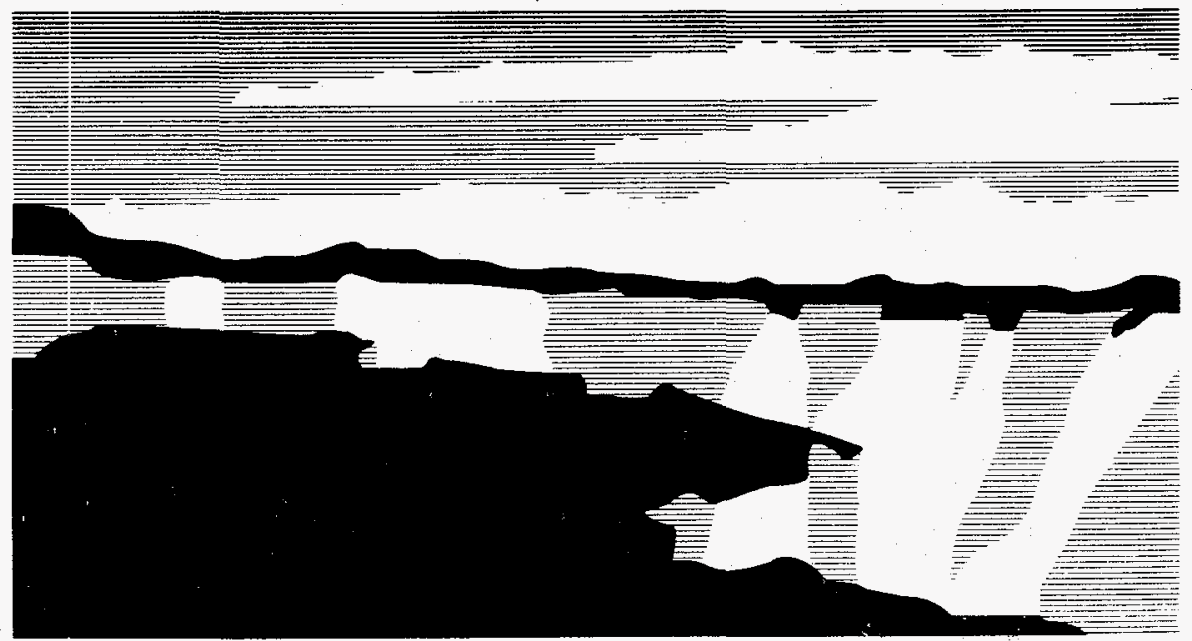

Los Alamos National Laboratory, an affirmative action/equal opportunity employer, is operated by the University of California for the U.S. Department of Energy under contract W-7405-ENG-36. By acceptance of this 3rticle, the publisher recognizes that the U.S. Government retains a nonexclusive, royalty-free license to publish or reproduce the published form of this contribution, or to allow others to do so, for U.S. Government purposes. The Los Alamos National Laboratory requests that the publisher identify this article as work performed under the auspices of the U.S. Department of Energy. 


\section{DISCLAIMER}

This report was prepared as an account of work sponsored by an agency of the United States Government. Neither the United States Government nor any agency thereof, nor any of their employees, makes any warranty, express or implied, or assumes any legal liability or responsibility for the accuracy, completeness, or usefulness of any information, apparatus, product, or process disclosed, or represents that its use would not infringe privately owned rights. Reference herein to any specific commercial product, process, or service by trade name, trademark, manufacturer, or otherwise does not necessarily constitute or imply its endorsement, recommendation, or favoring by the United States Government or any agency thereof. The views and opinions of authors expressed herein do not necessarily state or reflect those of the United States Government or any agency thereof. 


\section{DISCLAIMER}

Portions of this document may be illegible electronic image products. Images are produced from the best available original document. 


\title{
SENSITIVITY OF STABILITY INDICES TO DEALERTING
}

\author{
Gregory H. Canavan
}

A stability analysis derived from current U.S. and Russian analyses is used to study the impact of dealerting on stability, indicating that it could be negative.

Introduction. It is reported that "more than 100 former or current heads of state and civilian leaders from around the world, including ex-presidents Jimmy Carter and Mikhail Gorbachev, have signed a statement that calls for removing nuclear weapons from alert status and other measures aimed at the eventual elimination of atomic arsenals...reflecting mounting support for the cause of nuclear abolition..."1 This note uses stability analysis derived from current U.S. and Russian analyses to study the impact of such dealerting on stability, indicating that it could be negative.

Exchanges between mixes of vulnerable and survivable missiles forces are studied with an aggregated, probabilistic model, which optimizes each sides' first and determines each sides' second strikes and costs by minimizing first strike costs, ${ }^{2}$ in accord with published Russian metrics. ${ }^{3}$ Dealerting is modeled through reducing the alert rate of SSBN forces. The contributions from single-weapon ICBMs after START II are small. It is assumed that ICBMs could be alerted more rapidly, so they are treated as at full alert. Aircraft-borne weapons are not counted in the analysis below because they are too slow to participate in first strikes and inadequately survivable to participate in second strikes under projected conditions.

Forces used approximate those after START $\Pi{ }^{4}{ }^{4}$ They are roughly symmetric, thus, each side has 500 single weapon ICBMs and 336 SLBMs with five weapons each on 15 SSBNs. ${ }^{5}$ The two sides in the strategic exchange are labeled "unprime" and "prime" to maintain nationality neutrality, as dealerting and subsequent mobilization would have similar effects on both sides. The analysis predicts the first $(F)$ or second $(S)$ strikes unprime could deliver on prime and the first (F') or second ( $\left.S^{\prime}\right)$ strikes prime could deliver on unprime. ${ }^{6}$

Dealerting forces removes them from first and second strikes for as long as they are dealerted. If they are dealerted for periods long compared to those involved in the evaluation of first strike stability, dealerting has the same effect as permanent arms reductions, it subtracts them from first and second strikes. 'Thus, it is conceptually a way of implementing such reductions on an accelerated scale.

The effect of such reductions has been studied in earlier reports, ${ }^{7}$ which show that current and planned START I-II reductions would decrease first strike stability indices about $36 \%$ (from 0.55 to 0.35 ), the dealert of submarines would reduce the index by about another factor of three, and that the posited Russian shift to highly alert ICBMs would increase indices by about a factor 
of two. Generally, vulnerable forces on one side provides the opponent an opportunity to minimize damage to self by destroying them, which reduces his first strike cost and index.

Realerting. If one side could realert, i.e., mobilize, his strategic forces much faster than the other-or had hidden weapons, which serve much the same purpose-such rapid realerting would shift the balance from equal forces to one in which that side had a significant advantage. Those realerted forces would reduce the damage the other could produce in a first strike. The result of that advantage is studied below in terms of its affect on the allocation of first strikes, the magnitudes of those strikes, strike costs, and first strike stability indices.

Attack allocation. Figure 1 shows that as unprime's dealerting increases (his SLBM alert rate decreases), the unprime fractional allocation of his first strike to vulnerable prime missiles remains constant, while prime's allocation to vulnerable unprime missiles increases from about 0.2 to 0.4 in order to limit damage against the larger number of unprime missiles made vulnerable by dealerting.

Strikes. Figure 2 shows first and second strikes. Unprime's first strike does not change because his allocation does not change, but his second strike decreases monotonically as prime damage limits. Prime's first strike decreases slightly because of his increasing allocation to missiles, but his second strike does not change under unprime's optimal allocation.

Costs. Figure 3 shows the resulting first and second strike costs, which are the sum of the cost of damage to self and incomplete damage to the other. Unprime's first strike costs are constant, but his second strike cost increase because of the progressive reduction of his second strike. Prime's second strike costs increase slightly because his increasing allocation to missiles reduces damage to unprime value, but his first strike costs decrease sharply because of his progressive reduction of unprime's second strike.

Stability indices. Figure 4 shows the stability indices for each side, which are taken to be the ratio of their first and second strike costs, and the compound index, which is the product of the individual indices. For low dealert, the top curve is the stability index for prime, which decreases from about 0.85 at 0.15 to 0.25 at 0.95 ( $5 \%$ SSBN alert). The drop is due to sharp reduction in prime first strike cost at high dealert, which reduces unprime's second strike. The second curve is unprime's index, which falls from about 0.7 to 0.55 . The compound product thus falls from about 0.6 to 0.1 . The current nominal alert rate of 0.4 (dealert of 0.6 ) gives a compound index of 0.4 , so the reduction to an alert rate of $5 \%$ would give a reduction by a factor of $\approx 0.4 / 0.1 \approx 4$.

Summary and conclusions. Dealerting strategic forces has been posited as a stabilizing step towards their abolition. Previous reports have shown that planned START reductions will reduce stability indices by about a factor of two. Dealerting would hasten those reductions. They would also raise the possibility that one side could realert faster than the other. If so, the 
remobilized forces could be used to damage limit, which would reduce his first strike cost and stability index. The impact of complete demobilization of SSBNs would be an order of magnitude reduction in the overall stability index, to a level set by alert ICBMs. Generally, it would be preferable to maintain any existing strategic forces at the highest level of alert to minimize this effect and to concentrate instead on decreasing their total number.

\section{References}

1. B. Graham, "Carter, Gorbachev Join Call To Reduce Nuclear Threat," Washington Post, 2 Feb. 1998, p. A15.

2. G. Canavan, "Stability of Unsymmetric Forces," Los Alamos LA-UR-97-1133, March 1997.

3. A. Piontkovsky, "New Paradigm of Strategic Stability," A. Zichichi ed, International Seminar on Nuclear War and Planetary Emergencies (London, World Scientific, 1993).

${ }^{4}$. Treaty between the U.S. of America and the Russian Federation on Further Reductions and Limitation of Strategic Offensive Arms. [START II] (U.S. Government Printing Office).

5. D. Thompson, "The START Treaties: Implementation and Status," Los Alamos National Laboratory report LA-UR-97-2045, May 1997.

6. G. Kent and R. DeValk, "Strategic Defenses and the Transition to Assured Survival," RAND Report R-3369-AF, October 1986.

7. G. Canavan, "Sensitivity of Survivable Forces to Alert Rates," Los Alamos LA-UR-98-395, January 1998; G. Canavan, " Sensitivity to Alert Rates at Moderate Force Levels," Los Alamos LA-UR-98-471, January 1998. 


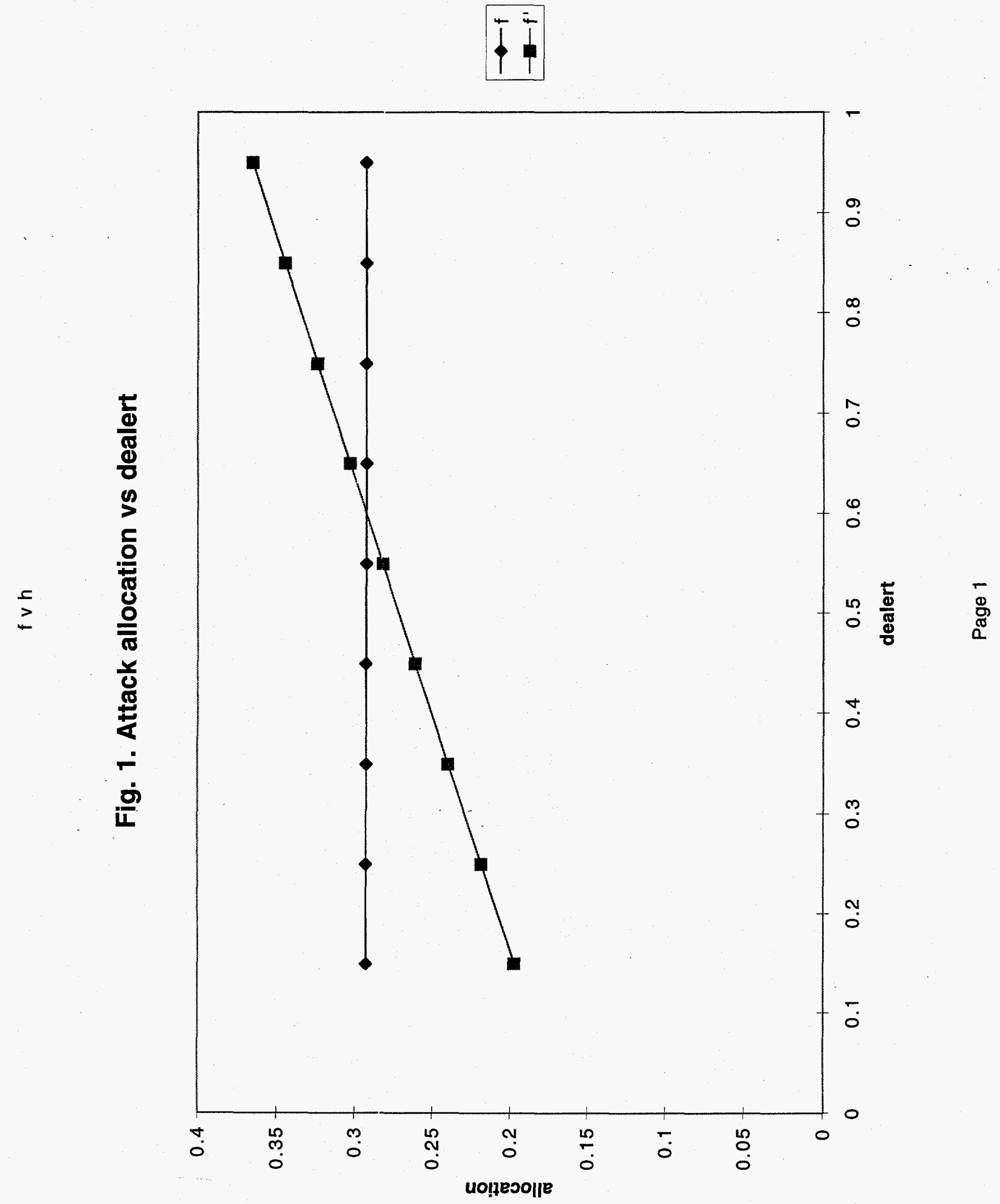



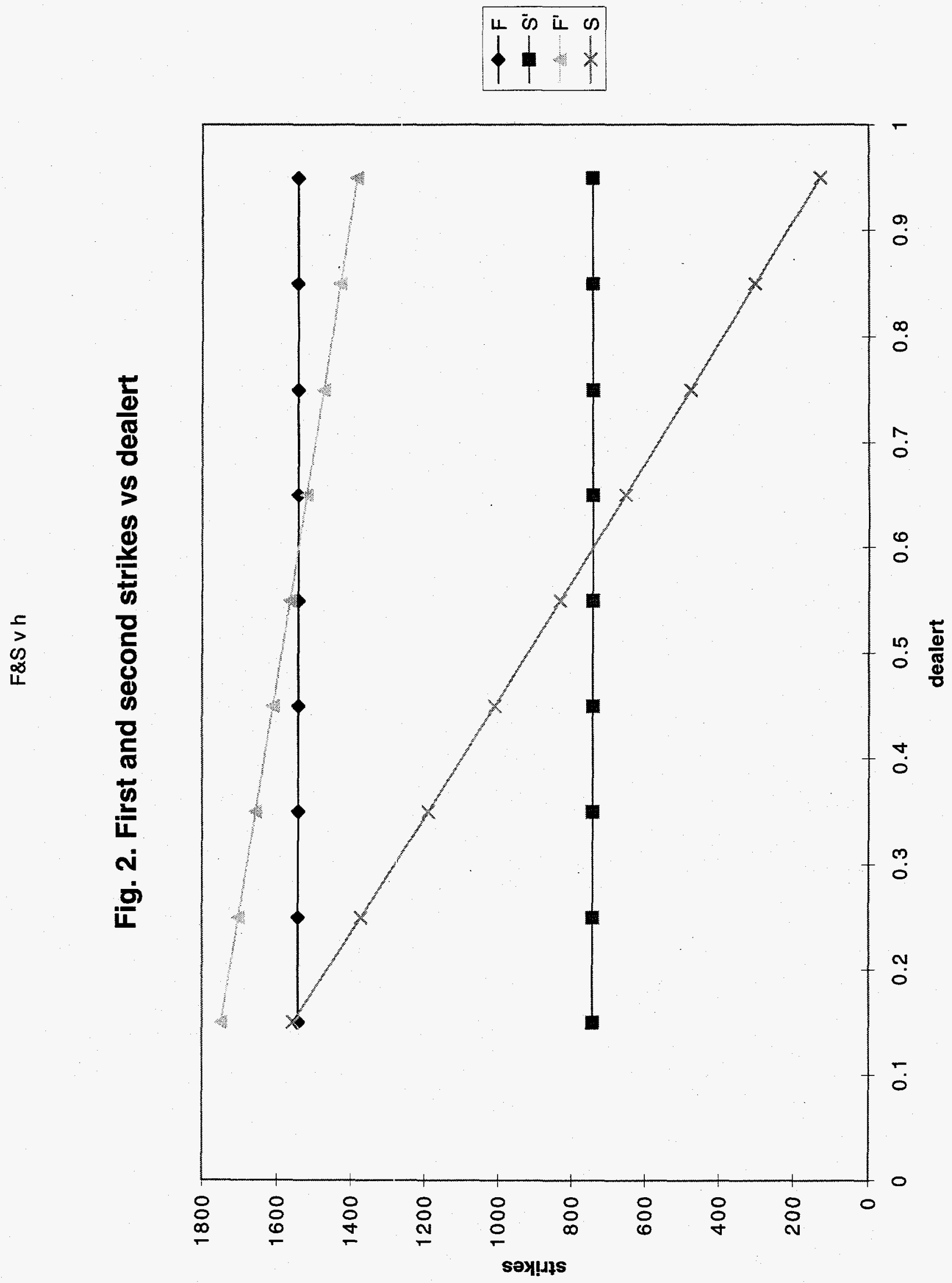


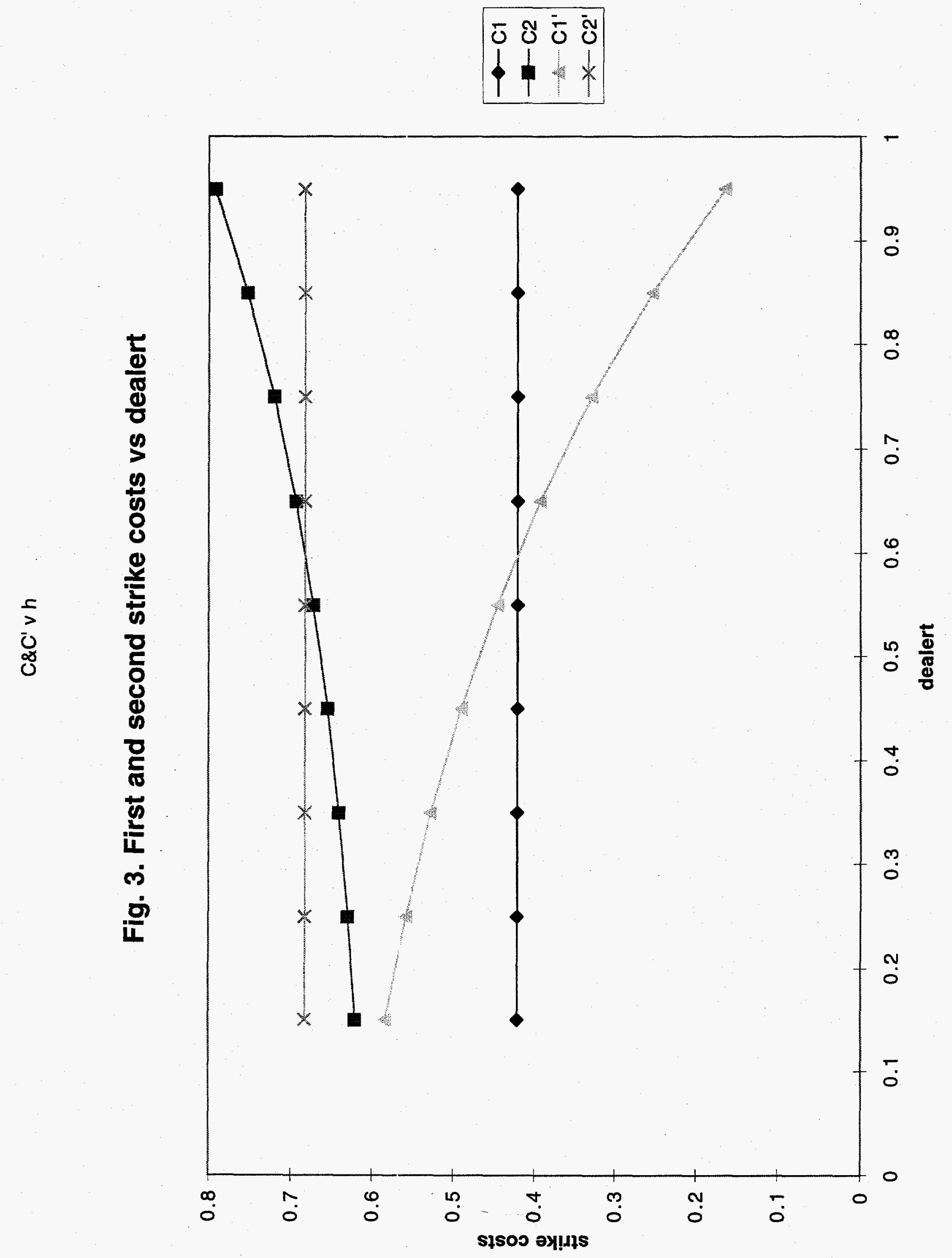




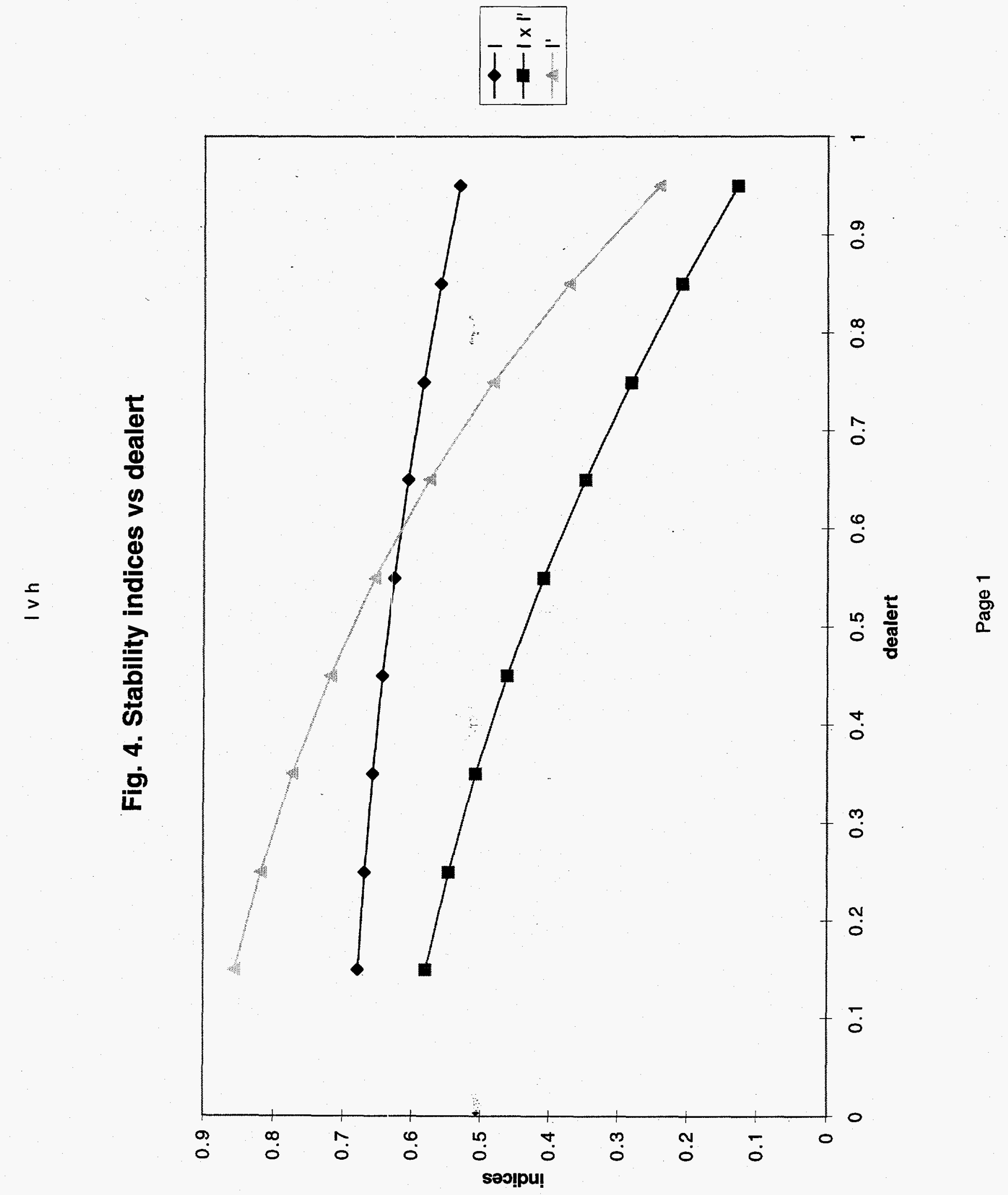

